\title{
Hereditary sensory and autonomic neuropathy type 5
}

INSERM

\section{Source}

INSERM. (1999). Orphanet: an online rare disease and orphan drug data base. Hereditary sensory and autonomic neuropathy type 5. ORPHA:64752

Hereditary sensory and autonomic neuropathy, type 5 (HSAN5) is characterized by loss

of pain perception and impaired temperature sensitivity, in the absence of any other major neurological anomalies. 